\title{
Identity Crisis and Inter-Ethnic Conflicts in Northern and Upper East Regions of Ghana
}

\author{
John Gasu \\ Department of Social, Political \& Historical Studies \\ University for Development Studies, Wa Campus, Ghana \\ gasujohn@yahoo.com \\ DOI//http://dx.doi.org/10.4314/gjds.v17i1.3
}

\begin{abstract}
The paper examines conflicts in Northern and Upper East regions of Ghana from the perspective of identity crisis in an ethnically heterogeneous section of the country. Notwithstanding the long periods of co-existence among the heterogeneous ethnic groups the melting pot effect has not emerged as attachment to primordial identity lines still prevail. This is most manifested between the traditionally acephalous societies and the chiefly societies. The relationship between these two societies has been antagonistic, especially as the acephalous societies seem to be besieged with identity crisis. The rejection of the chiefly hegemony is at the root of the identity conflicts. The cases examined in this paper illustrate two of such 'wars of emancipation' but with differential results. Whereas the Kusasi had been 'successful' in wrestling out of the chiefly hegemonic control of the Mamprusi, the Konkomba have not been all that successful against their antagonists. In both situations, however, the acephalous societies tend to slough off their past 'anarchic', systems to adopt and/or adapt the chiefly political culture. This adaptation has become the mode of assertion to redress the low social categorisation of the acephalous societies. It is concluded that observance of peace in two areas continue to be tedious as primordial cleavages are still alive. It is thus recommended, among others that the National Peace Council should work with stakeholders to sustain peace.
\end{abstract}

Keywords: Identity, Conflict, Kusasi, Mamprusi, Konkomba 


\section{INTRODUCTION}

Northern and Upper East regions of Ghana have gained notoriety for being conflict endemic parts of Ghana. News items emanating from the two regions are mostly for the wrong reasons, as they tend to be dominated by conflict and poverty related issues. The national government has continually imposed curfew on the people in the conflict endemic areas, as a way of curtailing their (re)occurrence but with minimal positive outcomes. The eruptions of communal violent conflicts have become not only unpredictable but also a perplexing matter for Ghanaian governments as the core issues are rather difficult to deal with in this multi-ethnic environment. The two regions have become a landscape that is awash with identity related conflicts that tend to perpetuate a vicious circle between poverty and conflicts (Brukum, 2002).

Some of these conflicts have been extensive in scope and severe in the scale of loss of lives and property; such that the very security of the Ghanaian state has often been threatened. Underlying the conflicts in this multi-ethnic, yet poverty stricken socioeconomic region, ${ }^{1}$ are issues that have to do with identity; and its corresponding psychological factor of recognition. Even though the pluralistic ethnic groups in this part of the country have lived together over the millennia, the apparent cultural similarity among its peoples has not really produced a melting pot effect that could erase the various primordial lines of affiliation and identity (Brukum, 2001). As a result, ethnic identity cleavages are still alive; though oftentimes latently, but easily manifest when ignited by very trite issues.

The covert nature that the identity contours assume, presents a façade to the real situation on the ground. The frequency and the level of destruction that is associated with the conflicts in these regions demand that we examine the problematic which such identity crisis pose to these societies. The interrogation of the core issues of conflict in this part of the country would, perhaps, enable us understand why these mainly poor peoples should be so devoted to enervating engagements that collectively sink them further into the deprivation abyss, rather than providing an opportunity for harnessing the synergy of diversity for development. It is important to note that the identity related conflicts are not limited to inter-ethnic relations alone but it also reflects in religious and intraethnic conflicts when secondary lines become the mode of reckoning in the identity definition.

1 The Ghana Living Standards Survey (GLSS) conducted by the Ghana Statistical Service since 1988 have shown that the administrative regions of Northern Ghana remain the poorest in the country. 
Even though a generic classification of ethnic groups can be made, it is worth adding that none of the ethnic groups in Northern Ghana is a homogeneous entity, as secondary lines of identity exist within them. The existence of these cleavages produce various levels of intensity of fissional forces that do manifest in the form of inter - and intra - ethnic conflicts. Consequently, there have been several manifestations of these identity-related conflicts but the focus of this article is on two of the inter-ethnic conflicts. The cases for examination are the inter-ethnic conflicts between the Konkombas and the Nanumbas; and also between the Mamprusis and Kusasis. The choice of the two cases is based on the persistence of what Brukum (2002) described as 'wars of emancipation' by the traditionally acephalous societies against the chiefly societies (cf. Fortes \& Evans-Pritchard, 1940). The interest in the choice of the cases also revolves around the differential outcomes of these 'wars of emancipation'.

The intensity and scope of these wars have also been phenomenal to warrant scrutiny. For instance, in the 1994 war between the Konkombas and the Nanumbas, the conflict went well beyond the territoriality of the two ethnic groups to virtually engulf the eastern part of Northern Ghana. This was the case because cognate chiefly ethnic groups like the Dagombas and the Gonjas quickly submerged their own differences to ally with the Nanumbas against their common foe, which the acephalous Konkombas represent. What was noticeable about the chiefly alliance against the Konkombas was that it was solidarity of the societies that had been instrumental in overrunning the Konkombas and subjecting them to feudalistic hegemonic control due to the latter's weak resistance character.

There was a corresponding reconfiguration of the identity map as the Konkombas also received support from other acephalous ethnic groupings - Basaris and Nawuris (Brukum, 2001). The shape that the alliances took is explicable by the historical contingencies that emerged since the initial contacts between the acephalous groups and the chiefly military campaigners (Maasole, 2006). Whereas the socioeconomic arrangements that have emerged between these two main groups currently convey little meaning to the Konkombas and hence their questioning of its legitimacy, the chiefly groups struggle to maintain the status quo.

Similarly, the perennial conflicts in Bawku between the Mamprusis and the Kusasis, present an identity issue between the previously acephalous Kusasis, and the chiefly Mamprusis. The Mamprusis came to establish chieftain suzerainty over the acephalous Kusasi group and subsequently established feudalistic arrangement with the latter. The urban nature of Bawku today, effectively conceals the dividing 
line between the two groups. This is because the warring ethnic groups had lived together for centuries; and through cohabitation and intermarriages have come to share many things in common including a mutually intelligible language.

Behind the frontage of a cultural convergence in both conflict situations are real issues of emotionally-loaded situations of identity that evoke primordial mechanical solidarity. The triggers of some of the conflicts judged on sober reflection present a pure case of collective lunacy; but that is exactly what the emotional investment in identity issues are all about. The trivial is given hyperbolic import and interpreted as a threat to the collective security and selfhood of a group.

\section{CONCEPTUAL ISSUES}

The concept 'ethnic group' is defined here as a collection of people who share the same primordial characteristics such as language, ancestry, religion and culture. The consciousness that arises out of these shared characteristics, and its expression by the group members to define themselves in relation to the significant others, is what is captured by the notion of 'ethnicity'. In other words, ethnicity refers to the behaviour and the feelings about oneself, and others, that emanates from being a member of an ethnic group (Asefa, 1996). The specific expression of that consciousness becomes a social mapping exercise that separates one group from the other; and this is expressed in an inclusive-exclusive social cleavage. The mapping system can either be presented on horizontal or vertical axis. And a mapping system that is both exclusive and vertical is potentially a conflict prone one; because of the inherent criteria of condescending views about societies that are seen as immutably inferior. A vertical ethnic structure is thus one in which some ethnic groups are placed in superordinate position vis-à-vis others; with the corresponding identity and recognition accorded the subordinate groups captured in the myth of their irredeemable low status.

Related to the issue of ethnic group and ethnicity is, therefore, the case of 'identity'. In social context, 'identity' connotes the distinctive features that differentiate a person or a collective from the others. What distinguishes one group from the others usually springs from two main sources: from the inherent group's specific qualities such as those based on primordial relations and socio-economic criteria. The awareness that a bundle of shared features separates one group from all others is critical, in this regard. This creates a dichotomy between the collective self, and the relevant others within the social perceptual field, that is marked by symbolic cognitive guideposts. The symbols that define a group evoke both a sense 
of collective security, and a source of psychic gratification for its members. It is for this reason that groups define themselves in a positive light, as it is within that psychological frame that they will realise the sense of selfhood.

What defines a group can also be extraneously imposed by the significant others; and oftentimes the elements that are employed, in cases of that sort, are mainly those fed by stereotypes. Taylor (1994) points out that identity issues are inherently political because it ultimately rests on the issue of recognition. In this regard, “...one's inner self is just not a matter of inward contemplation; it must be intersubjectively recognised if it is to have value" (Fukuyama, 2006: 9). The recognition that a group demands from others should go beyond those based on shared humanity, especially when the identity and recognition is being requested by the vertically lowly placed groups.

In all cases of identity mapping, a binary is created that may either be evinced by perceptual lines of demarcation or the reality of what separates one group from the other. It should be recognised that the defining components of a particular group identity are not eternally unchallengeable since the conceptual elements are also subject to the dynamics that correspond with social transformative processes.

This is not to say that all the stakeholders in a particular social interactive process are always aware, and/or even prepared to accept an emerging antithesis. Since identity issues are rich in emotional investment, the inability to realise the dialectics of change by a party in the interactive situation forms the basis for conflicts. The search for an identity and its favourable projection in relation to the relevant others, is a very powerful psychological driving force behind human civilisation. It is in this sense that identity issues become sensitive since we are after all dealing with a mythological community that embraces all the power necessary for political mobilisation. Viewed this way, group identity also becomes coterminous with an abiding sense of selfhood; the core of which makes life meaningful and predictable to an individual within the group (Northrup, 1989).

The common denominator that defines a group's identity, in reality goes beyond the psychological as it also translates into the physical and spiritual security. Events that tend to invalidate the core sense of a group's identity, therefore, elicit defensive responses that aim at avoiding psychic and/or physical annihilation. It is important to add that the security that identity provides is only attainable and sustained when the elements that go into the said definition of the group, emanate from its members and have become accepted without question (Taylor, 1994). 
The same cannot be said of a group's identity criteria when it is determined from without. This is because the definitional elements from without are often loaded with pejorative ideas; and in such cases the extraneously defined identity poses a threat to the group's sense of collective security and dignity. When the components of a group's identity run into incongruity with the externally determined ones then we are confronted with identity crisis. The resolution of which is for any group in question to fight back for the restoration of the psychological and physical fulfilments that all ethnic groups cherish. It is from this background of conceptual clarifications that I move into the examination of the two cases under focus.

\section{The Konkomba Relations with their Chiefly Neighbours}

The Konkombas have always had tedious relationship with their chiefly neighbours: Dagombas, Nanumbas and the Gonjas. The differentials that existed between the segmentary social formations of the autochthonous Konkombas and the invading chiefly ethnic groups, largely accounted for the easy fall of the Konkombas (Tait, 1964). The literature is abundant with accounts of how the horsemen of the Dagomba sacked the Konkombas from their original settlements in Chare ${ }^{2}$ (Yendi) which created room for the seizure of their land (Brukum, 2001; Fynn, 1971). Unable to match the superior military might of the other invading groups, like the Gonjas and the Nanumbas, the Konkombas in retreat took refuge in the floodable fringes of River Oti (Tait, 1964).

Thus, the genesis of the antagonism is rooted in the nature the contacts between the Konkombas and the chiefly ethnic neighbours, took. The traditional way of life of the Konkombas, and the other acephalous societies was subsequently lost as their autonomy and the sense of selfhood dissipated. The Konkombas became a subject people to their victorious chiefly neighbours (Maasole, 2006; Brukum, 2001). However, the legitimacy of the political suzerainty exercised by the conquerors was hardly accepted by the Konkombas, and hence power over the Konkombas often took the form of coercion. This was to have far reaching implications in the social and economic relations between the Konkombas and the chiefly ethnic groups.

Various feudal predatory socio-economic arrangements were imposed on the Konkombas by the Dagombas, Nanumbas and the Gonjas. It is worth noting that the arrival of the chiefly groups in Northern Ghana marked the integration of the area into the Trans-Saharan trading system (Der, 1998; Goody, 1971). The role of

2 Chare was the Konkomba settlement where Yendi, the current traditional capital of the Dagombas is now located. 
the chiefly ethnic groups in the trading system was simple but counterproductive: they exchanged slaves for horses and weapons from the west Sudan traders. The horses and weapons were needed for military expeditions to satisfy atavistic needs; and the "payoff was human booty, captives to be sold as slaves" (Goody, 1971: 36). The linkage between horse imports and the imperial drive of the chiefly societies meant that slaves mainly from the Konkomba enclaves and outliers fed well into the 'trading system' (Der, 1998).

Things did not change any better for the acephalous societies when the Ashanti in central Ghana, under Opoku Ware, defeated the northerly chiefdoms in 1744 and then superimposed a tribute payment socioeconomic structure on the subdued northerly chiefdoms (Rattray, 1932). ${ }^{3}$ What this meant for the Konkombas, in particular, was their subjugation to a vassalage position to the second degree. They were now to directly meet the needs of their immediate northern lords and then meet the second order requirements from Ashanti (Brukum, 2001; Staniland, 1975). This translated into the stoppage of the slave export commodity northwards; they were now sent southwards via Kumasi with their final destination in the Americas (Der, 1998). This went on for 170 years until it was abolished in 1874 by the British colonial authorities (Rattray, 1932). Since the chiefly groups of the Gonja, Dagomba and Nanumba were the ones that controlled the means of destruction the Konkomba and the other acephalous groups suffered most from the ensuing rapacious drives.

The colonial abolition of slave raiding was only good to the extent that it replaced the more obnoxious forms of economic appropriation for the subtle ones. There was an adaptation that took the form of paying heavily for the office of the chieftaincy by using the chieftain position to collect tributes of various kinds and to extort the Konkombas especially through the traditional court system. Tait related the Dagomba-Konkomba relationship as follows, and I quote in extenso:

Relations between the two groups have been hostile and (continue to be) ... so today. Dagomba 'rule' was limited to sporadic raids to obtain slaves needed for the annual tribute to Ashanti. Today the sporadic raiding continues in a different form. From time to time collectors are sent to the Konkomba territory to collect corn which is sold in the markets to raise money. When the YaNa was fined by the District Commissioner's court in 1950, no fewer than two lorry loads of sorghum was collected in the Saboba region alone on

3 The chiefdoms that were defeated by the Ashantis were Gonja and Dagomba. 
the grounds that 'The European says it has to be paid' In the same year some Konkomba were stopped by Dagomba on their way to the Yendi market and their headloads of new yams taken, on the grounds that they had paid no tribute to the YaNa (Tait, 1964: 9).

The Konkomba in Nanumba areas also faced similar extortionist demands from their Nanumba political overlords. Skalnik also describes this relationship as follows:

The Konkomba accepted the conditions of Nanumba chiefs of paying allegiance to the latter they were expected to pay annual labour to the chiefs...(also) they had to bring all the cases to the chief's judicial courts and they were obliged to bring the hind leg from the first animal slaughtered at funerals or killed at hunts (Skalnik, 1985).

This was an effort to deprive the Konkomba elders any juridical authority over their own people since allowing that would be tantamount to diverting attention away from the dominant locus of authority. What was necessary in this respect was to ensure an absolute subservience of the Konkombas to their overlords.

The colonial administration was to accentuate the position of the chiefs by making them the linchpin of the indirect rule system. Since chiefs were pivotal in the implementation of the indirect rule system, an easy way was found in Northern Ghana by placing the acephalous societies under identifiable chiefdoms. This eventuated in further crowding out of the acephalous societies from any position of significance in the colonial governance structure. This was done irrespective of its attendant legitimacy problems. Skalnik underscored this problematic in relation to the Konkombas' role in the governance structure as follows:

The Konkomba are among those ethnic groups classified as segmentary or acephalous, who were without a state and were chiefless. The colonial administration and postcolonial regimes, not only in Ghana, were known for siding with those groups which had chiefs and states and centralization of political office. These groups were, at least partners with the Europeans. The 'anarchic tribes such as the Konkomba could not be partners (Skalnik, 1985).

What the colonial authorities aimed at achieving was to strengthen the positions of the traditional chiefdoms through the grant of judicial and quasi-legislative powers 
such that they could become effective partners in the colonial administration (Kimble, 1963).

In this way, the anonymity of the Konkombas among the colonial traditional political office holders' was assured due to their 'anarchic character'. The circumstances that the indirect rule generated made the Konkombas even more susceptible to the traditional judicial exploitation, mainly due to the breaches of their apparent antediluvian intergenerational marriage arrangement (Maasole, 2006). The traditional child betrothal arrangements among the Konkombas have faced difficulties in contemporary times. The traditional marriage arrangement allows older Konkomba men to betroth the girl-child. These men then pay part of their bride-price to their prospective in-laws in terms of labour till the girls are of age for marriage. But in many cases the young ladies rather got attracted to their young male counterparts, when they are of age for marriage. This has resulted in cases of aggrieved jilted males bringing such matters of betrothal breaches for settlement at the chiefs' courts; and the local magistrate courts (Maasole, 2006). The courts found it profitable to prey on this type of situation. Commenting on this situation Skalnik said...

The authorities in both instances (chiefs and governmental magistrates) were not really familiar with the intricacies of Konkomba marriage custom but they knew very well that the Konkomba are very ready to give anything for the solution of their disputes. This was used to the arbitrators' advantage as they normally demanded remuneration (in money or kind) from both sides in the dispute (Skalnik, 1983: 19).

The profitability of the appropriation scheme through the court system made the chiefly groups to hold a monopolistic control over all modes of arbitration.

As a subject people, the semi-nomadic culture of the Konkombas also came under stress. The Konkomba peasant had lost the free movement on the abundant land that they thought they had both allodial and usufructory rights, which was in tune with their aboriginal claims. The nomadic culture was mainly due to the way they determined soil fertility. The soil was considered fertile if it supported luxuriant growth of grass. And with this mode of reckoning soil fertility, the Konkomba farmer would usually relocate if the grass cover on a particular piece of land became stunted (Skalnik, 2014; Maasole, 2006). But the loss of land entitlements also meant constraint on the Konkombas' free access to land outside the enclaves they now 
find themselves. Attempts by the Konkombas to engage in treks in search for more fertile lands only ended in redefining them as 'settlers' by their 'hosts.' ${ }^{4}$

\section{The 1994 Guinea Fowl War}

In the ranked social context in which the Konkombas found themselves it was obvious that their identity tag within the ethnic matrix was a lowly placed one that clashes with the sense of psychic gratification, selfhood, and security that an ethnic identity provides. The identity crisis that it generated brought forth the question as regards who the Konkombas really were, especially as they relate to the chiefly societies. As answers to this question became evasive, the Konkombas began to reject the contemptible manner in which they were held. Consequently they began to see ethnicity in all their dealings with all the significant others. The Konkombas began to take advantage of the environment that the country's political independence provided to become assertive in reclaiming their lost image. The Konkomba Youth Association (KOYA) which was formed in the 1970 s by the educated youth and business interests became the platform on which the Konkombas began to galvanise their energies to redress issues related to their servility to the chiefly societies of the Nanumba, Dagomba and Gonja (Maasole, 2004; Brukum, 2001). The corrosion of the traditional chiefly authority in the aftermath of Ghana's political independence, made it possible for the KOYA to begin posing questions about their collective status that their forebears could not muster enough cerebral fortitude to openly ask (Maasole, 2004). The contradictions between the identity definitions the Konkombas gave themselves and the answers received from without inevitably created a sense of identity discordance. The resolution of the emergent psychological dissonance led the Konkomba into various forms of conflict with the chiefly societies. The KOYA began to decry their relationship with the chiefly societies as being one of 'hewers of wood and drawers of water.' 5

The KOYA became voluble in pointing out the exploitative regime that Konkombas had lived over the years (Pul, 2003). In this respect, the KOYA believed it was time, they as a people were granted traditional authority and recognition so that they could run their own affairs. It is in this light that the KOYA in conjunction with the

4 There had been a movement of Konkombas westwards in the 1930 s resulting in a number of conflicts with other ethnic groups. The Konkomba movements in the period have been attributed to the Konkomba attempts to flee from the French rigorous modes of tax collection in Togoland.

5 See the Petition sent by the Konkomba Youth Association (KOYA) on 29 June 1993 for the creation of a paramountcy for them to be known as Ukpakpabur. 
Saboba-Na (the chief of Saboba) ${ }^{6}$ made a number of petitions to the National House of Chiefs ${ }^{7}$ on 29 June 1993. The petition demanded the upgrading of the Saboba-Na to a paramount status; and the obvious basis of this request was the rejection of the hegemonic control of the chiefly ethnic groups. The petition to the National House of Chiefs was for the creation of a traditional paramountcy for the Konkomba land to be known as 'Ukpakpabur' that will have a 'defined territorial area of their own'. In the view of the Konkombas this petition was made to "encourage the development of each ethnic identity and promote inter-tribal co-operation and bring trust, confidence and peaceful coexistence among all the tribes of the North" (emphasis mine). ${ }^{8}$

The petition was deliberately sent to the National House of Chiefs without routing it through the YaNa who holds traditional lordship over the area, which the proposed Konkomba chiefdom was to be created (Oelbaum, 2010). The YaNa rejected the Konkomba request based on the implications which the granting of it would bring. For the YaNa and the rest of the chiefly societies, the Konkombas have no allodial claims over land, since they were either considered as settlers or conquered people (Skalnik, 2014; Pul, 2003). In other words, in the bundle of elements that define the Konkomba, land ownership does not exist and since the traditional notion of chiefdom cannot be divorced of landownership, it therefore goes without saying that the Konkomba request could not be met (Skalnik, 2014).

The Konkombas saw in the denial an attempt by the Dagombas to perpetuate their hegemonic control over them. For the Konkombas the benefits which the Dagomba chiefs did not want to relinquish include the juridical extortionism, labour on the chiefs' farms, donation of the hind leg of the first cow killed during funeral and also of those animals killed during hunting, and providing grain stock for the chiefs.

The YaNa also rejected the KOYA petition to the National House of Chiefs on procedural grounds and demanded that the petition should have been routed through him. But the Konkombas rather saw this as the capitalisation on the trivial, in the wake of the gravity of their grievances. As the avenues for constructive engagement were closed, the Konkombas began undercover preparations for more robust engagements to redeem their identity and recognition.

6 The Konkomba consider Saboba as their traditional political capital.

7 The National House of Chiefs is the umbrella body of the traditional authorities in Ghana.

8 Konkomba Youth Association (KOYA) petition 29 June 1993. 
But the efforts by the Konkombas to redeem their battered image seemed not to produce the desired results. This is evidenced, for instance, in the scornful manner the Nanumbas continued to hold them. Skalnik wrote about this as follows:

They (the Konkombas) were viewed as savages uncivilised 'bush people' and despised... the Nanumba certainly did not fear the Konkomba; they rather looked upon them with condescension (Skalnik, 1983: 19).

Obviously the Konkombas were frustrated by the indelible negative print they had carried throughout the period they had been in contact with their chiefly neighbours. And as such they began to prepare for a more vigorous engagement with their neighbours to dispel the negativity they had suffered over the years. ${ }^{9}$ After covert preparations, what was needed to kick start the war was a spark that was provided by hagglers' disagreement over the price of a guinea fowl at the village market of Nakpayili. On 31 December 1993 a Konkomba man made a failed attempt to buy a dark guinea fowl from another Konkomba man who had brought the bird for sale in the village market at Nakpayili (Mahama, 2003). The traditional mode of commodity transaction is usually one of bargaining from polar opposites until an agreement is reached. But in the case of this guinea fowl the two Konkomba men failed to reach an agreement (Mahama, 2003). A prospective Nanumba buyer stood by, and took advantage of the failed deal to offer a higher price that got him the bird. The failed Konkomba buyer was hurt, as he accused the successful Nanumba man for being the cause for his inability to strike the deal (Mahama, 2003). A brawl ensued as tempers between the competitors became uncontrollable. And within the social context in which events were unfolding identity issues quickly drew mechanical solidarity along primordial lines for the two fighters. These fighters unwittingly became the precursors of an extensive inter-ethnic war. The initial fight was carried to the following day when the successful Nanumba buyer was killed on the farm. Thence, the battle lines were drawn and the Konkomba mobilisation for its execution took off with alacrity against their chiefly enemies. From this point, the Konkombas became relentless in their attack against the Nanumba, Dagomba and the Gonja (Mahama, 2003).

It is this linkage with the commonplace bird that provided the journalese description of the war as the 'Guinea-Fowl War'. While this caption may be right in relating the war to its immediate trigger, it is obviously trivialisation of the underlying

9 The Konkombas fought the Dagombas in 1981. More than 500 lives were lost. Villages were torched leading to displacement of people. 
forces that were responsible for the scope and the monstrosity of the conflict. ${ }^{10}$ The enormity of its scale is appreciated not only in the unprecedented loss of lives and property but also in the halting of economic activity in the country's most povertyendemic area. The altercation at the village market was certainly a camouflage that concealed the inner feelings of a deep-going bifurcated identity lines between the Konkomba and the chiefly ethnic groups that the hagglers represented. The type of weaponry and their professional execution of this particular war amply suggest a well-thought-out Konkomba planning. ${ }^{11}$ The outrageous nature of the hostility and the ethnic alliances that were built tell a story of a vertically layered identity characterisation that had existed between the chiefly ethnic groups, on one hand and the acephalous ethnic groups, on the other hand.

The war quickly spread from its initial domain in Nanumba land to Dagbon and then to Gonja. The fast spread of the war theatre was partly due to the Konkombas indiscriminate attack on all the chiefly ethnic groups; and also due to the instinctive mechanical support that the Nanumbas received from their cognate chiefly societies. Thus what initially began in the obscure village of Nakpayili soon engulfed a large territory and involved a multiple of ethnic groups. The Konkombas similarly received support from other acephalous ethnic groups like the Nawuris and the Basaris to prosecute the war (Mahama, 2003). The Nawuris and the Basaris by the nature of their social formations had also suffered similar modes of exploitation and demeaning circumstances as the Konkombas. Hence the Konkombas, Basaris and Nawuris came to share common enemies, which were the chiefly ethnic groups.

The war which began on the last day of 1993 persisted well into 1994 with massive destruction. The central government was baffled by the developments in the area, and imposed a state of emergency to curtail the conflict. ${ }^{12}$ But this was an unconventional warfare in which the frontlines were not properly defined, and hence it was even difficult for the Ghana military to intervene successfully. It was not until 9 June, 1994 that the combatants signed a peace treaty to cease hostilities. The state of emergency which was imposed in February, however, stayed till August when it was revoked by Parliament. The war led to the destruction of 442 villages and resulted in the displacement of over 200,000 people. In terms of the number

10 The War covered a large part of eastern part of Northern Ghana. The spillover was felt in the form of communal violence in the country's capital - Accra.

11 Among the weapons used in the war were AK 47. It is not too clear how the rural peasants came to acquire such weapons.

12 The state of emergency which was imposed on 10 February 1994 covered the following districts: Yendi, Nanumba, Gushiegu/Karaga, Saboba/Chereponi, East Gonja, Zabzugu/Tatale and Tamale. In addition the government closed four border posts in the area with Togo to present the conflict from spreading. 
of deaths, figures vary from official estimates of 2,000 to Oxfam's figure of 15, 000 (van de Linde \& Naylor, 1999: 27).

\section{Bawku: Mamprusi-Kusasi Conflicts}

Bawku presents another case of conflicts between an acephalous ethnic group and a chiefly group. The Kusasis were traditionally acephalous but came under Mamprusi chiefly hegemonic control some two-and-half centuries ago. Accounts on the Mamprusi control of the Kusasi vary but there is a pointer to the effect that the Kusasis were not militarily conquered. In fact, the historical accounts indicate that the antagonistic relationship between the Kusasis and the Mamprusis began since Mamprusi hegemony over the Kusasis started in their early contacts (Opoku-Afari Committee, 1957). The Nayiri Atabia ${ }^{13}$ sent Prince Ali to safeguard the trade route between Nalerigu ${ }^{14}$ and Mossi land (in Burkina Faso) against the alleged Kusasi banditry on the profitable slave and commercial route (Awedoba, 2010; Kusimi et al., 2006; Rattray, 1932). Out of this initial Mamprusi settlement emerged a political chieftain control over the acephalous Kusasi. Their numerical preponderance, notwithstanding, the Kusasi came to acquiesce to a form of traditional colonial arrangement that made a Mamprusi the paramount chief (Naba) of Bawku. The Mamprusi traditional colonial structure was feudalistic, as tribute-paying machinery was imposed on a people that were only organised in segmentary forms. The socioeconomic superstructure that the Kusasi were overlaid with, meant a redefinition of their identity in relation to the significant others. In this case, it was principally a measurement against the Mamprusis.

With the loss of their traditional autonomy, the Kusasis were now effectively being controlled by the Mamprusi oligarchy. In line with the traditional feudalistic arrangement the Kusasi began to serve as a labour force for the Mamprusi chiefs in Bawku and in the outlier communities (Opoku-Afari Committee, 1957). The acephalous character of the Kusasi culture made their subservience to centralised political control an onerous one, as that was alien to their own political culture. Since the political subjugation also went with the re-arrangement of the power matrix, it meant also that the Kusasi in the eyes of their political overlords were now of the lower 'caste'.

The sense of selfhood, security and pride that the Kusasis previously associated with their ethnic identity was now to contend with the low esteem which the

13 Nayiri is the traditional title of the paramount chief of the Mamprugu state.

14 Nalerigu is the traditional capital of Mamprugu. 
Mamprusis came to hold them. It was this bruised collective ego of the Kusasis that drew them into antagonistic relations with the Mamprusis. The Kusasis detested the idea that even though they were not militarily conquered they should lose the dignity of self-rule even if their traditional mode of social organisation was relatively a primitive one.

Once the Kusasis had lost their traditional self-rule, what colonialism did was to further undercut any move towards autonomy. The efficiency associated with the indirect rule system in Northern Ghana specifically made the recognition of the Mamprusi hegemony unassailable during the colonial period. The Mamprusis, therefore, enjoyed a privileged position in the colonial scheme; this situation ran parallel to the marginality of the acephalous Kusasis in the traditional colonial political office holders (Hilton, 1962). ${ }^{15}$

The protestations of the Kusasis during the colonial era were subdued by the exigencies of colonial authoritarian control. The situation began to change in 1957 when a new Bawku Naba was to be installed to replace a deceased one. The opportunity brought into being the usual competition and rivalry between the eligible princes. On 6 July 1957 at Nalerigu, the Nayiri installed Prince Mahama Yeremia as the new Bawku Naba. However, unknown to the Mamprusi chieftain while they were in Nalerigu, the Kusasis organised themselves and elevated one of the Tindana (land priest) Abugurago Azoka as the new Bawku Naba (see Bombande, 2007). What emerged was the installation of two Bawku Nabas, one in Nalerigu (Mamprusi) and the other in Bawku (Kusasi) to engage in zero-sum contest for the occupancy of the traditional office (Opoku-Afari Committee, 1957).

In the wake of the emerging troubling situation the Mamprusis now faced, the other princes that previously disapproved of Mahama Yeremia's installation quickly sank their own differences to rally behind their kinsman to fight the Kusasi challenge ${ }^{16}$. Even though Kusasi revolts had dogged their uneasy historical relations since their earliest contacts, the civil unrests and the associated communal violence between the two ethnic groups exacerbated since the Kusasi began installing their own chiefs as Bawku - Naba.

15 The British colonial authorities recognised the Mamprusi dynasty and rule over the Kusasi since indirect rule system placed premium on the recognition of chiefs.

16 The Mamprusi protested against the installation and the recognition of the Kusasi Abugurago Azoka as the Bawku Naba at the High Court which was upheld but was subsequently appealed against by Kusasis in which the Chief Justice Sir Arku Korsah overturned the decision of the High Court. Thence the conflict assumed political dimensions as Opoku-Afari was perceived as a pro-CPP person bent on uplifting the Kusasi. 
Clearly, the Kusasi effort and 'success' in overturning the Mamprusi chiefly hegemony have been an exercise to redefine the Kusasis in relation to the significant others especially the Mamprusis. Perhaps it could be said to be an effort that rejected the shadowy existence of the Kusasis and to place them in the manner that is consistent with their own estimation. Patriliny among both the Mamprusis and the Kusasis define their allegiance and ethnicity; and this line is not blurred by cohabitation or/and intermarriages. The perpetual pre-occupation with whether the Mamprusi or the Kusasi should be the one that occupies the highest level in the perceptual social mapping has always kept alive the mutual suspicion. Political control, or the lack of it, has always evoked some amount of emotional responses; as the exercise of political power is always associated with the subjugation of those who are subject to it (Lund, 2003). For this reason there is always the natural inclination of a people to accept the exercise of political power by one's own kind rather than a foreigner or one who is perceived as such. Freedom and liberation fighters all over the world have this denominator in common. The chieftaincy conflicts in Bawku have all along been between the Mamprusis, who are struggling to restore the status quo ante and self-esteem as the traditional chieftain overlords, and the Kusasis who have rejected the low status that their previous acephalous social arrangement had provided them. The various expressions of the contests have led to numerous communal conflicts in Bawku over the years to date. The repetitive character the conflicts have taken currently projects an image of impotency on the part of the state to resolve the issue.

This is largely because since independence the matter of who becomes a Bawku Naba had taken political dimensions (Kusimi et al., 2006). The Kusasi cause had had support from Kwame Nkrumah's Convention People's Party (CPP) and this was transmitted through the successes that Kusasis chalked in the Courts during the period of Nkrumah's rule. With the overthrow of Nkrumah in 1966, the military government of the National Liberation Council (NLC) passed the Chieftaincy Amendment Decree, NLCD 112 (1966) to depose the Kusasi Bawku Naba Abugurago Azoka (Bombande, 2007; Mensah-Brown, 1969). With the coming into power of the Jerry John Rawlings' Provisional National Defense Council (PNDC) government passed the Restoration of Status of Chiefs Law, the PNDC Law 75 to restore the Abugurago dynasty as the Bawku Naba (Bombande, 2007). This was effected through the enskinment of Ninchema Abugrago Azoka II, son of the first Kusasi Bawku Naba Abugrago Azoka, as the new Bawku Naba. The politicisation of the conflict has been deepened with the return to multiparty democracy in Ghana. The Kusasis are mainly supporters of the National Democratic Congress (NDC), while 
the Mamprusi sympathies are with the New Patriotic Party (NPP). In the polarised political atmosphere in Ghana between the NDC and the NPP, the volatile situation in Bawku has rendered the town a zone for proxy wars that are fought after every general election. ${ }^{17}$

The usual response of governments has been the imposition of curfews. However the imposition of curfews in the area and the heavy presence of the security forces have not served as effective deterrence in curbing the violence. Oftentimes, the violence is sparked off by very mundane situations as disagreements over the location of a bus station by lumpen elements that, for predatory reasons populate the bus terminals; this was exactly the case in 2001.

\section{CONCLUSION}

The two cases examined provide evidence of how ethnic societies that were previously acephalous seek to redress their identity issues and their subservience to the chiefly societies that they are in contact with. The contexts in which the cases are examined are similar but locations are separated from each other. There are also discernible differentials in the outcomes of the two struggles. Whereas the Kusasis have been more successful in overturning the ethnic prestige table, the Konkombas notwithstanding the prolonged and destructive wars with the chiefly societies have not really succeeded in redeeming their lost aborigine rights.

The efforts by the acephalous societies in question, undoubtedly, have been to recompose the elements that define their identity in a way that would at least place them on the horizontal plane rather than being at the lower end of a vertical scale. What is evident in both cases is the sloughing off of the 'anarchic' culture by either fully adopting the chiefly political culture or displaying tendencies towards that goal. The Konkomba in this regard have not been successful in their demand for the establishment of their own chiefdom that was to be christened Ukpakpabur. The Kusasi on the other hand have been able to overturn the tables against the Mamprusis but this 'victory' is at a great cost of perpetual loss of life. This is the case because both sides of the Bawku conflict have resorted to arms to either restore the status quo ante or to upend it.

The differentials in outcomes of these struggles can be attributed to the fact that whereas the Konkombas have at least three chiefly ethnic groups - Dagombas, Nanumbas and Gonjas - to contend with, the Kusasis in Bawku have only the Mamprusis to deal with. The numerical strength of the combined forces that

17 The Kusasi and Mamprusi clashes in Bawku in recent times occurred in 1983, 1984, 1985, 2000, 2001, 2007, 2008, 2009 and 2010. 
the Konkombas have to fight, in order to make their case is an enormous one, in relation to their own population. The Kusasis are, however, fighting the Mamprusis that are numerically inferior to them.

It can also be said that even though the two acephalous contenders - Konkombas and the Kusasis - took advantage of the more liberal environment that the country's political independence has engendered to pursue their respective agendas, the Kusasis had added benefits by way of central government support and favourable judicial decisions. This has not been available to the Konkombas per se.

In any case it is incontrovertible to state that the two acephalous ethnic groups in question have now gained some respect from their former overlords as the latter is forced to negotiate peace agreements with the ethnic groups that were previously held in contempt. The wars which Brukum (2002) alluded to as liberation struggles are not conclusive yet but the identity definition of the Konkombas and the Kusasis are definitely changing for the better.

\section{RECOMMENDATIONS}

The conflicts examined in this article touch on a fundamental psychological issue of identity and the social recognition it confers on a people as they relate to significant others. In the scheme of things, the perceptual mapping of the ethnicities correlates very much with power and control within the traditional governance matrix. The persistence and the protracted nature of the two conflicts are due to the inherent psychology that is associated with identity crisis. These issues will not be easy to deal with, especially as they take the shape of zero-sum outcomes in the occupancy of chieftain positions. The partisan political affiliations with the parties in conflict have weakened the central government's position to resolve the matters.

Notwithstanding these issues, the following recommendations are made to deal with the conflicts in the two areas examined. It is recommended that:

1. The state agency - National Peace Council - should work together non-state peace-based organisations to proactively engage with the belligerents to deal with the issues in contention.

2. The National Centre for Culture should organise inter-cultural festivals on regular basis for a better appreciation of the ethnic groups in conflict; and finally,

3. The state should ensure permanent security presence in the areas in conflict so as to reduce the phenomenon of state absence. 


\section{REFERENCES}

Asefa, H. (1996). Ethnic Conflict in Horn of Africa in Rupesinge \& Tiskov (Eds.), Ethnicity and Power in the Contemporary World. United Nations University Press.

Awedoba, A. K. (2010). An Ethnography Study of Northern Ghanaian Conflicts: Towards Sustainable Peace. Sub-Saharan Publishers.

Bombande, E. (2007). Conflicts, Civil Society Organisations and Community Peacebuilding Practices in Northern Ghana. In: S. Tonah (Ed.), Ethnicity, Conflicts and Consensus in Ghana, 196-228. Woeli Publishing Services.

Brukum, N. J. K. (2001). The Guinea Fowl, Mango and Pito War Episodes in the History of Northern Ghana, 1980-1999. Ghana Universities Press.

Brukum, N. J. K. (2002). Ethnic Conflicts in Northern Ghana between1980-1999: An Appraisal. Transactions of the Historical Society of Ghana New Series Nos. 4 \& 5 Trondheim Historical Society of Ghana: 131-147.

Der, B. G. (1998). The Slave Trade in Northern Ghana. Woeli Publishing Services.

Pul, H. (2003) 'Exclusion, Associations and Trend and Triggers in Northern Ghana's Konkombas-Dagomba Wars' The African Anthropologist 10(1). 39-82.

Fortes, M. (1940). The Political Systems of the Tallensi of the Northern Territories of the Gold Coast: In M. Fortes, and E. E. Evans-Pritchard (1940). African Political Systems. Oxford University Press.

Fukuyama, F. (2006). Identity, Immigration \& Democracy. Journal of Democracy 17(2), 5-20.

Fynn, J. K. (1971). Asante and its Neighbours 1700-1807. Longman.

Goody, J. S. (1971). Technology, Tradition and the State. Oxford University Press.

Hilton, T. E. (1962). Notes on the history of the Kusasi in Transactions of Historical Association of Ghana, VI, 79-86.

Kimble, D. (1963). A Political History of Ghana: 1850-1928. Clarendon Press.

Kusimu, J., Fobil, J., Atubuga, R., Erawoc, I., \& Oduro, F. (2006). Conflicts in Northern Ghana: A mirror of answers to sub-regional stability and security questions. Journal of Asteriskos, 1(2), 209-228.

Lund, C. (2003). Bawku is still volatile: Ethno-political conflicts and state recognition in Northern Ghana. Journal of Modern African Studies, 414, 587-610.

Maasole, C. S. (2004). The Formation of Youth Associations; the Development of the Konkomba Youth Association and Inter-Ethnic Conflicts in Northern Ghana 
Paper presented at Department of Social, Political and Historical Studies University for Development Studies Seminar Wa Campus February.

Maasole, C. S. (2006). The Konkomba and Their Neighbours: A Study of Inter-Ethnic Conflicts in Northern Ghana from the Earliest Times to 1914. Ghana Universities Press.

Mahama, I. (2003). Conflicts in Northern Ghana, Tamale, Cyber Systems.

Northrup, T. A. (1989). The Dynamic of Identity in Personal and Social Conflict. In L. Kriesberg, T. A. Northrup \& S. J. Thorson (Eds.), Intractable Conflicts and Their Transformation (pp. 55-82). Syracuse University Press.

Oelbaum, J. (2010) Spatial Poverty Traps and Ethnic Conflicts Traps: Lessons for Northern Ghana's 'Blood Yams' ODI Working Paper 324, CPRC Working Paper 164, December.

Opoku-Afari Committee. (1957). Bawku affairs: Report of the committee appointed by His Excellency the Acting Governor-General to inquire into the claim of Abugurago Azoka to have been elected or appointed and installed as chief of the Kusasi Area. Accra: Registry, Court of Appeal.

Pul, H. (2003). Exclusion, Associations and Trend and Triggers in Northern Ghana's Konkombas-Dagomba Wars. The African Anthropologist, 10(1), 39-82.

Rattray, R. S. (1932). Tribes of Ashanti Hinterland Vol. 1 \& 2. Oxford University Press.

Skalnik, P. (1983). Questioning the concept of the State in Indigenous Africa. Social Dynamics, 9(2), 11-28.

Skalnik, P. (1985). Chieftaincy and the State: The Dragging History of NanumbaKonkomba Conflict. Ghana Newsletter No. 17 Nov. 4-22.

Skalnik, P. (2014). Political Anthropology of History: The Case of Nanum of Northern Ghana. Social Evolution \& History, 13(2), 57-72.

Staniland, M. (1975). The Lions of Dagbon: Political Change in Northern Ghana. Cambridge University Press.

Tait, D. (1964). The Konkomba of Northern Ghana. Oxford University Press.

Taylor, C. (1994). Multiculturalism Examining the Politics of Recognition. Princeton University Press.

van de Linde, A and Naylor R. (1999). Building Sustainable Peace: Conflict Conciliation and Civil Society in Northern Ghana. Oxfam GB. 